\title{
Expression of interleukin-1 (IL-1), IL-6, and tumor necrosis factor- $\alpha$ (TNF- $\alpha$ ) in non-small cell lung cancer and its relationship with the occurrence and prognosis of cancer pain
}

\author{
Yuanming Liu ${ }^{1 \#}$, Yan Gao ${ }^{2 \#}$, Tao $\mathrm{Lin}^{3}$ \\ ${ }^{1}$ Department of Respiratory and Critical Care Medicine, People's Hospital of Pengzhou, China; ${ }^{2}$ Department of Oncology, People's Hospital of Pidu \\ District, China; ${ }^{3}$ Department of Anesthesiology, Sichuan Provincial People's Hospital, University of Electronic Science and Technology of China \& \\ Chinese Academy of Sciences Sichuan Translational Medicine Research Hospital, Chengdu, China \\ Contributions: (I) Conception and design: Y Liu, T Lin; (II) Administrative support: T Lin; (III) Provision of study materials or patients: Y Liu, Y \\ Gao; (IV) Collection and assembly of data: Y Liu, Y Gao; (V) Data analysis and interpretation: Y Liu, Y Gao; (VI) Manuscript writing: All authors; (VII) \\ Final approval of manuscript: All authors. \\ "These authors contributed equally to this work. \\ Correspondence to: Tao Lin. Department of Anesthesiology, Sichuan Provincial People's Hospital, University of Electronic Science and Technology \\ of China \& Chinese Academy of Sciences Sichuan Translational Medicine Research Hospital, No.32 West 2nd Section, 1st Ring Road, Chengdu \\ 610072, China. Email: wangxiaocdqy2020@163.com.
}

Background To analyze the expression of interleukin-1 (IL-1), IL-6, and tumor necrosis factor- $\alpha$ (TNF- $\alpha$ ) in non-small cell lung cancer (NSCLC) and its relationship with the occurrence and prognosis of cancer pain.

Methods: A total of 113 NSCLC patients (NSCLC group) in People's Hospital of Pengzhou from March 2019 to March 2020 were enrolled, and 109 healthy volunteers (control group) in the same period were selected. The expression levels of IL-1, IL-6, and TNF- $\alpha$ in different populations and in patients with different degrees of cancer pain were compared. Pearson test was used to analyze the correlation between IL1 , IL-6, TNF- $\alpha$ and cancer pain. Multivariate logistic regression was used to analyze the risk factors affecting the poor prognosis of NSCLC patients. Receiver operating characteristic (ROC) curve was drawn to analyze the predictive value of IL-1, IL-6 and TNF- $\alpha$ for poor prognosis of NSCLC.

Results: The levels of IL-1, IL-6, and TNF- $\alpha$ in the NSCLC group were significantly higher than those in the control group $(\mathrm{P}<0.05)$. According to the Visual Analogue Scale (VAS) scores, 61 cases were divided into the mild group (VAS $\leq 3$ points) and 52 cases were divided into the severe group (VAS $>3$ points). The levels of IL-1, IL-6, and TNF- $\alpha$ in the severe group were significantly higher than those in the mild group $(\mathrm{P}<0.05)$. Multivariate logistic regression analysis showed that clinical stage, lymph node metastasis, differentiation, and IL-1, IL-6, and TNF- $\alpha$ levels were independent risk factors for the poor prognosis of NSCLC patients $(\mathrm{P}<0.05)$. Age, sex, and tumor diameter were not prognostic risk factors $(\mathrm{P}>0.05)$. The sensitivity and specificity of IL-1 + IL- 6 + TNF- $\alpha$ combined for the prediction of poor prognosis of NSCLC were $81.80 \%$ and $71.40 \%$, respectively, while the AUC was 0.846 (95\% CI: 0.753-0.929), which was significantly higher than that predicted by IL-1, IL-6, and TNF- $\alpha$ alone $(\mathrm{P}<0.05)$.

Conclusions: The expression levels of IL-1, IL-6, and TNF- $\alpha$ in NSCLC patients were significantly upregulated, and were closely related to the occurrence and prognosis of cancer pain in patients.

Keywords: Interleukin-1 (IL-1); tumor necrosis factor- $\alpha$ (TNF- $\alpha$ ); non-small cell lung cancer (NSCLC); cancer pain; prognosis

Submitted Nov 08, 2021. Accepted for publication Dec 15, 2021.

doi: 10.21037/apm-21-3471

View this article at: https://dx.doi.org/10.21037/apm-21-3471 


\section{Introduction}

The incidence and mortality of lung cancer are high, while the survival rate remains low. According to relevant data, the 5 -year survival rate of lung cancer patients is only $15 \%$. Non-small cell lung cancer (NSCLC) accounts for more than $80 \%$ of the total incidence of lung cancer. NSCLC patients are prone to tumor invasion of peripheral blood vessels, which results in distant metastasis and affects the prognosis of patients (1). Therefore, improving the accuracy of early diagnosis has a positive impact on improving the prognosis of patients. Cancer pain is a common symptom affecting the quality of life of patients. Most studies have shown that cancer pain in cancer patients is closely related to the level of cytokines (2). Interleukin-1 (IL-1) is an active inflammatory cytokine and an important member of the interleukin family, which can enhance the host's immune response in vivo or in vitro (3). IL-6 is a cytokine with extensive biological effects, which is closely related to tumor growth (4). Tumor necrosis factor- $\alpha$ (TNF- $\alpha$ ) is a multifunctional inflammatory cytokine which stimulates the release of IL-1 $\beta$ and IL-6 (5). Studies have established animal models found that the implantation of homologous MRMT-1 breast cancer cells in rat bone marrow cavity can induce typical pain behavior changes in rats, and studies have found that with the destruction of cancerous bone and the aggravation of tumor load in rat peripheral blood IL-1, IL-6, TNF- $\alpha$, prostaglandin E are highly expressed, these factors are released by tumor tissue, resulting in changes in the expression of signal peptide and growth factor. The results show that peripheral nerve pain is sensitive, pain threshold is reduced, and the pain feeling is expanded (6). At present, there are few studies on the relationship between IL-1, IL-6, TNF- $\alpha$ and cancerous pain in NSCLC patients and the prognosis of patients with three-factor joint evaluation. Based on this, this study analyzes the expression of IL-1, IL-6, and TNF- $\alpha$ in NSCLC patients and aims to understand its correlation with cancer pain and the prognosis of NSCLC, so as to provide a reference for clinical diagnosis and treatment. We present the following article in accordance with the STARD reporting checklist (available at https://dx.doi.org/10.21037/apm-21-3471).

\section{Methods}

\section{General information}

A total of 113 patients with NSCLC (NSCLC group) admitted to People's Hospital of Pengzhou from March
2019 to March 2020 were enrolled, including 69 males and 44 females, aged $40-78$ years, with an average age of $53.68 \pm 4.16$ years. The inclusion criteria were as follows: (I) NSCLC patients diagnosed by clinical pathology; (II) complete clinical data; (III) patients signed informed consent. The exclusion criteria were as follows: (I) Patients with malignant tumors, nephrotic syndrome, tuberculosis, and other diseases; (II) chemoradiotherapy and surgical treatment were performed before admission; (III) patients with other pulmonary diseases; (IV) the expected survival time was less than 3 months. In addition, 109 healthy volunteers (control group) in the same period in our hospital were selected, including 61 males and 48 females, aged 40-78 years old, with an average age of $53.57 \pm 4.31$ years old. There was no significant difference in general data between the 2 groups, and they were comparable $(\mathrm{P}>0.05)$. All procedures performed in this study involving human participants were in accordance with the Declaration of Helsinki (as revised in 2013). The study was approved by ethics committee of People's Hospital of Pengzhou (No. 2020010) and informed consent was taken from all the patients.

\section{Study methods}

Detection methods of IL-1, IL-6, and TNF- $\alpha$

Fasting venous blood $(3 \mathrm{~mL})$ was obtained from patients the next morning after admission and on the morning of physical examination for participants in the control group. Serum was obtained after centrifugation of the samples at 2,000 r/min for $5 \mathrm{~min}$. IL-1, IL-6, and TNF- $\alpha$ were detected by enzyme-linked immunosorbent assay (ELISA) using the Multiskan Ascent automatic enzyme labelling instrument and IL-1, IL- 6 , and TNF- $\alpha$ reagents provided by Genzyme company. The assay procedures were performed in accordance with the kit instructions.

\section{Assessment of cancer pain}

The Visual Analogue Scale (VAS) was used to evaluate the cancer pain of patients. The total score was 10 points, where 0 was painless, $\leq 3$ was painless or mild pain, and $>3$ points indicated pain affecting sleep and even strong unbearable pain (7).

\section{Prognostic evaluation}

The general data of patients were collected, including age, gender, clinical stage (I-II, III-IV), lymph node metastasis (yes, no), tumor diameter $(\geq 5,<5 \mathrm{~cm})$, differentiation degree 
Table 1 Comparison of IL-1, IL-6, and TNF- $\alpha$ levels in different populations $(\bar{x} \pm \mathrm{s})$

\begin{tabular}{lcccc}
\hline Group & Cases & $\mathrm{IL}-1(\mu \mathrm{g} / \mathrm{mL})$ & $\mathrm{IL}-6(\mathrm{ng} / \mathrm{mL})$ & $\mathrm{TNF}-\alpha(\mathrm{pg} / \mathrm{mL})$ \\
\hline Control group & 109 & $0.11 \pm 0.06$ & $50.11 \pm 10.84$ & $21.65 \pm 5.06$ \\
NSCLC group & 113 & $1.05 \pm 0.21$ & $72.77 \pm 11.49$ & $46.77 \pm 7.25$ \\
$t$ & - & 44.991 & 15.103 & 29.836 \\
$\mathrm{P}$ & - & $<0.001$ & $<0.001$ & $<0.001$ \\
\hline
\end{tabular}

IL, interleukin; TNF- $\alpha$, tumor necrosis factor- $\alpha$; NSCLC, non-small cell lung cancer.

Table 2 Comparison of IL-1, IL-6 and TNF- $\alpha$ levels in NSCLC patients with different degrees of cancer pain $\left(\bar{x}_{ \pm} \mathrm{s}\right)$

\begin{tabular}{lcccc}
\hline Group & Cases & $\mathrm{IL}-1(\mu \mathrm{g} / \mathrm{mL})$ & $\mathrm{IL}-6(\mathrm{ng} / \mathrm{mL})$ & $\mathrm{TNF}-\alpha(\mathrm{pg} / \mathrm{mL})$ \\
\hline Mild group & 61 & $0.81 \pm 0.15$ & $63.26 \pm 10.31$ & $38.81 \pm 5.76$ \\
Severe group & 52 & $1.33 \pm 0.27$ & $83.94 \pm 12.37$ & $56.11 \pm 8.10$ \\
$t$ & - & 12.893 & 9.693 & 13.248 \\
$\mathrm{P}$ & - & $<0.001$ & $<0.001$ & $<0.001$ \\
\hline
\end{tabular}

IL, interleukin; TNF- $\alpha$, tumor necrosis factor- $\alpha$; NSCLC, non-small cell lung cancer.

(low differentiation, medium-high differentiation), and IL1, IL-6, and TNF- $\alpha$ levels. Patients were followed up for 12 months to determine metastasis and death, and patients were divided into a poor prognosis and good prognosis group.

\section{Observation indicators}

The levels of IL-1, IL-6, and TNF- $\alpha$ in different groups were compared. The correlations between IL-1, IL-6, and TNF- $\alpha$ levels and VAS scores were analyzed. The predictive value of IL-1, IL- 6 and TNF- $\alpha$ on the prognosis of NSCLC was calculated.

\section{Statistical analysis}

The data were analyzed by SPSS 20.0 software. Measurement data were expressed as mean \pm standard deviation $(\bar{x} \pm \mathrm{S})$ and analyzed by the $t$ test. Count data were expressed as rates or constituent ratios and the $\chi^{2}$ test was used. The correlations between IL-1, IL- 6 , and TNF- $\alpha$ levels and VAS scores were analyzed by the Pearson test. Multivariate logistic regression analysis was used to analyze the risk factors affecting the poor prognosis of NSCLC patients. A receiver operating characteristic (ROC) curve was generated to analyze the predictive value of IL-1, IL6 , and TNF- $\alpha$ levels for the poor prognosis of NSCLC, and the area under the curve (AUC) was calculated. $\mathrm{P}<0.05$ indicated that the difference was statistically significant.

\section{Results}

Comparison of IL-1, IL-6, and TNF- $\alpha$ levels in different populations

The levels of IL-1, IL-6, and TNF- $\alpha$ in the NSCLC group were significantly higher than those in the control group $(\mathrm{P}<0.05)$, as shown in Table 1.

\section{Comparison of IL-1, IL-6 and TNF- $\alpha$ levels in NSCLC patients with different degrees of cancer pain}

According to the VAS score, 61 cases were divided into the mild group (VAS $\leq 3$ points) and 52 cases were divided into the severe group (VAS $>3$ points). The levels of IL$1, \mathrm{IL}-6$, and TNF- $\alpha$ in the severe group were significantly higher than those in the mild group, and the difference was statistically significant $(\mathrm{P}<0.05)$, as shown in Table 2 .

\section{Correlations between IL-1, IL-6, and TNF- $\alpha$ levels and VAS scores}

Levels of IL-1, IL-6, and TNF- $\alpha$ were positively correlated with VAS scores $(\mathrm{P}<0.05)$, as shown in Table 3 and Figure 1. 


\section{Analysis of risk factors affecting the poor prognosis of NSCLC patients}

According to the follow-up data, 84 patients had good prognosis and 29 patients had poor prognosis. Clinical stage, lymph node metastasis, differentiation, and IL-1, IL-6, and TNF- $\alpha$ levels were the single factors affecting the poor prognosis of NSCLC patients $(\mathrm{P}<0.05)$, while age, gender, and tumor diameter were not risk factors influencing the prognosis of patients $(\mathrm{P}>0.05)$, as shown in Table 4.

\section{Multivariate analysis of poor prognosis in NSCLC patients}

Multivariate logistic regression analysis showed that clinical stage, lymph node metastasis, degree of differentiation, and IL-1, IL-6, and TNF- $\alpha$ levels were independent risk factors for the poor prognosis of NSCLC patients $(\mathrm{P}<0.05)$, as shown in Table 5 and Table 6.

Table 3 Correlations between IL-1, IL-6, and TNF- $\boldsymbol{\alpha}$ levels and VAS scores

\begin{tabular}{lcc}
\hline Index & \multicolumn{2}{c}{ VAS } \\
\cline { 2 - 3 } & $\mathrm{r}$ & $\mathrm{P}$ \\
\hline $\mathrm{IL}-1$ & 0.461 & 0.002 \\
$\mathrm{IL}-6$ & 0.699 & $<0.001$ \\
TNF- $\alpha$ & 0.618 & $<0.001$ \\
\hline
\end{tabular}

IL, interleukin; TNF- $\alpha$, tumor necrosis factor- $\alpha$; VAS, Visual Analogue Scale.

\section{The predictive value of IL-1, IL-6, and TNF- $\alpha$ for the poor prognosis of NSCLC}

According to the ROC curve, the sensitivity and specificity of IL-1 + IL- 6 + TNF- $\alpha$ combined for the prediction of poor prognosis of NSCLC were $81.80 \%$ and $71.40 \%$, respectively, with an AUC of 0.846 (95\% CI: 0.753-0.929), which were significantly higher than those predicted by IL-1, IL-6, and TNF- $\alpha$ alone $(\mathrm{P}<0.05)$, as shown in Table 7 and Figure 2.

\section{Discussion}

The interleukin family is closely related to the occurrence of inflammation in the body. Many studies have also shown that its genotyping is closely related to the occurrence and development of NSCLC (8). IL-1 is an active inflammatory cytokine produced by cells involved in the immune response during the process of antigen presentation or antigen uptake to form antibody complexes. The binding of IL-1 to the corresponding receptor can induce the biological effects of immune cells and increase the body's immune response (9). IL-1 is a multifunctional cytokine in NSCLC pathology and cell physiology, and has gradually become a hot topic in clinical research. In previous studies, IL-1 has been found to play an important role in a variety of tumors, participating in tumor angiogenesis, the secretion of growth factors, and tumor metastasis, and is also closely related to prognosis $(6,10)$. IL-6 is an important member of the interleukin family, and previous studies have shown that IL-6 has an important pro-inflammatory effect in a variety
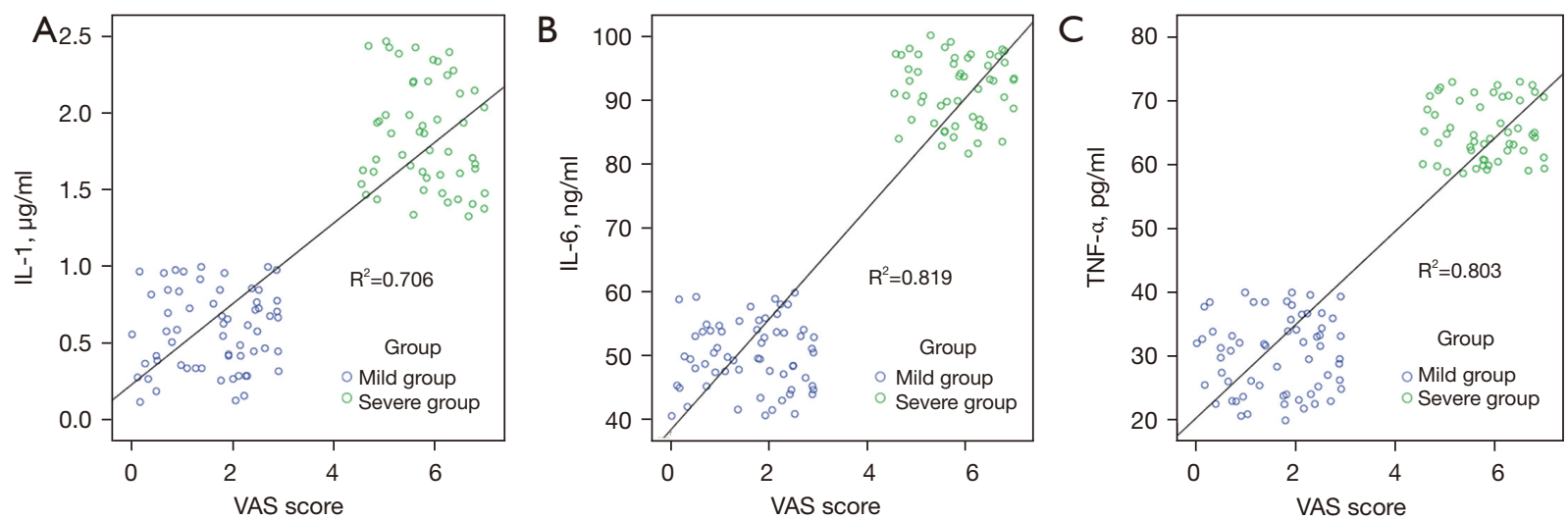

Figure 1 Correlations between IL-1, IL-6, and TNF- $\alpha$ levels and visual analogue scale (VAS) scores. (A) scatter plot of the correlation between IL-1 level and VAS score; (B) scatter plot of the correlation between IL-6 level and VAS score; (C) scatter plot of the correlation between TNF- $\alpha$ level and VAS score. IL, interleukin; TNF- $\alpha$, tumor necrosis factor- $\alpha$; VAS, Visual Analogue Scale. 
Table 4 Analysis of risk factors affecting the poor prognosis of NSCLC patients

\begin{tabular}{|c|c|c|c|c|}
\hline Factor & Good prognosis $(n=84)$ & Poor prognosis $(n=29)$ & $\chi^{2}$ & $\mathrm{P}$ \\
\hline$\geq 53$ & 38 & 18 & & \\
\hline$<53$ & 46 & 11 & & \\
\hline Gender & & & 2.682 & 0.101 \\
\hline Female & 29 & 15 & & \\
\hline Clinical stages & & & 23.278 & $<0.001$ \\
\hline I-II stage & 69 & 10 & & \\
\hline III-IV stage & 15 & 19 & & \\
\hline$<5 \mathrm{~cm}$ & 34 & 11 & & \\
\hline Differentiation degree & & & 5.845 & 0.015 \\
\hline Poorly differentiated & 39 & 21 & & \\
\hline Moderately well differentiated & 45 & 8 & & \\
\hline $\mathrm{IL}-1(\mu \mathrm{g} / \mathrm{mL})$ & & & 7.154 & 0.007 \\
\hline$\geq 1.08$ & 31 & 19 & & \\
\hline$<1.08$ & 53 & 10 & & \\
\hline IL-6 (ng/mL) & & & 21.826 & $<0.001$ \\
\hline
\end{tabular}

NSCLC, non-small cell lung cancer; IL, interleukin; TNF- $\alpha$, tumor necrosis factor- $\alpha$.

Table 5 Significance and assignment of factors to be analyzed

\begin{tabular}{lll}
\hline Factor & Representative meaning & Assignment \\
\hline$X_{1}$ & Clinical stages & $0=$ I-II stage; 1= III-IV stage \\
$X_{2}$ & Lymph node metastasis & $0=$ No; $1=$ Yes \\
$X_{3}$ & Differentiation degree & $0=$ Moderately-well differentiated; $1=$ Poorly differentiated \\
$X_{4}$ & IL-1 & $0=<1.08(\mu \mathrm{g} / \mathrm{mL}) ; 1=\geq 1.08(\mu \mathrm{g} / \mathrm{mL})$ \\
$X_{5}$ & IL-6 & $0=<72.77(\mathrm{ng} / \mathrm{mL}) ; 1=\geq 72.77(\mathrm{ng} / \mathrm{mL})$ \\
$X_{6}$ & TNF- $\alpha$ & $0=<46.77(\mathrm{pg} / \mathrm{mL}) ; 1=\geq 46.77(\mu \mathrm{g} / \mathrm{mL})$ \\
\hline IL, interleukin; TNF- $\alpha$, tumor necrosis factor- $\alpha$. &
\end{tabular}

IL, interleukin; TNF- $\alpha$, tumor necrosis factor- $\alpha$. 
Table 6 Multivariate analysis of poor prognosis in NSCLC patients

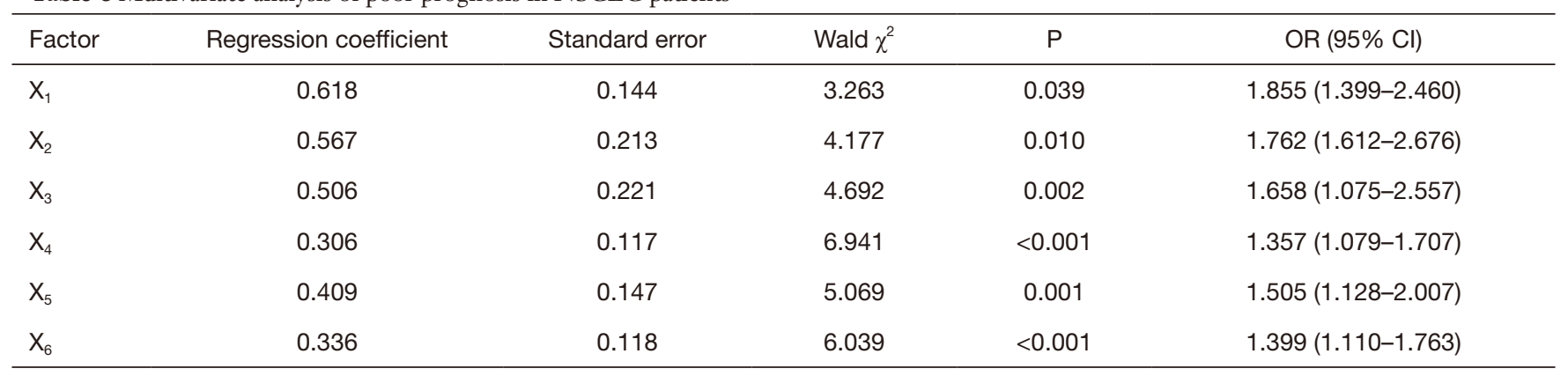

NSCLC, non-small cell lung cancer; OR, odds ratio.

Table 7 Predictive value of IL-1, IL-6, and TNF- $\alpha$ levels for the poor prognosis of NSCLC

\begin{tabular}{lcccc}
\hline Factor & AUC & $95 \%$ Cl & Sensitivity & Specificity \\
\hline IL-1 & 0.711 & $0.617-0.829$ & 0.679 & 0.592 \\
IL-6 & 0.736 & $0.679-0.875$ & 0.698 & 0.653 \\
TNF- $\alpha$ & 0.799 & $0.733-0.901$ & 0.717 & 0.677 \\
IL-1 + IL-6 + TNF- $\alpha$ & 0.846 & $0.753-0.929$ & 0.818 & 0.714 \\
\hline
\end{tabular}

IL, interleukin; TNF- $\alpha$, tumor necrosis factor- $\alpha$; NSCLC, non-small cell lung cancer; AUC, area under the curve.

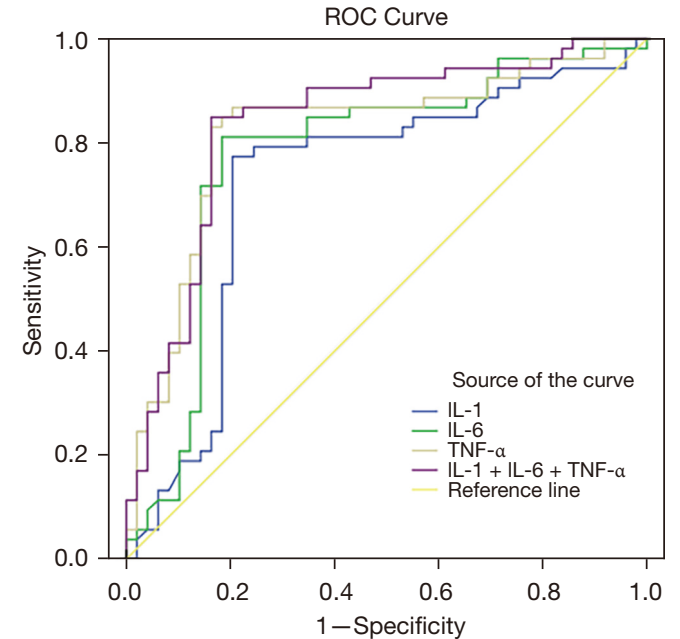

Figure 2 ROC curve of IL-1, IL-6, and TNF- $\alpha$ levels in predicting the poor prognosis of NSCLC. ROC, receiver operating characteristic; IL, interleukin; TNF- $\alpha$, tumor necrosis factor- $\alpha$; NSCLC, non-small cell lung cancer.

of inflammatory reactions and diseases $(11,12)$. IL-6 can be secreted by macrophages, fibroblasts, $\mathrm{T}$ lymphocytes, and other cells (13). Some studies have found that with the improvement of health, the expression level of IL-6 can be decreased to a certain extent and can gradually return to a healthy level, which may be due to the fact that IL-6 activates $\mathrm{T}$ lymphocytes while inducing $\mathrm{B}$ lymphocyte differentiation and promotes immunoglobulin secretion $(14,15)$. IL-6 can be self-induced in some tumor cells, thereby promoting the growth of tumor cells $(16,17)$. TNF- $\alpha$ is produced by eosinophils and monocytes, and is a multifunctional inflammatory factor. It can mediate the aggregation of lymphocytes and eosinophils at the inflammatory site and can stimulate the production of IL6 , IL-8, and other factors. It can also inhibit the apoptosis of eosinophils, make eosinophils aggregate and activate, and synthesize fiber cells and colony stimulating factors in the vascular endothelium, so as to promote the persistent inflammatory response of the body (18).

In this study, it was found that the levels of IL-1, IL-6, and TNF- $\alpha$ in NSCLC patients were significantly higher than those in the control group. Combined with the above literature, it was suggested that IL-1, IL-6, and TNF- $\alpha$ were closely related to the development of NSCLC. With the aggravation of cancer pain in patients with NSCLC, the levels of IL-1, IL-6, and TNF- $\alpha$ in the blood of patients also showed a gradual upward trend, and were positively correlated with VAS pain scores. This suggests that the levels of IL-1, IL-6, and TNF- $\alpha$ increased with the increase 
of cancer pain intensity, which can provide a reference for the evaluation of cancer pain in patients. In order to prevent cancer pain, it is necessary to strengthen the treatment of tumors, avoid the deterioration of cancer progression, reduce the risk of metastasis and recurrence of tumors, and use analgesic drugs to relieve pain when necessary; patients need active cooperation with doctors. The analysis of risk factors showed that IL-1, IL-6, and TNF- $\alpha$ were independent risk factors for the poor prognosis of NSCLC patients, which was consistent with the results of previous literature (19). An ROC curve was further generated, and it was found that IL-1, IL-6, and TNF- $\alpha$ had a certain value in predicting the prognosis of patients, and the sensitivity and specificity of combined detection were higher than those of the 3 alone, suggesting that the changes in the IL-1, IL-6, and TNF- $\alpha$ levels of patients can provide an important reference for the evaluation of prognosis.

In summary, the expression levels of IL-1, IL-6, and TNF- $\alpha$ in NSCLC patients were significantly up-regulated, which was closely related to the occurrence and prognosis of cancer pain. These findings may provide new ideas for prognosis evaluation and cancer pain treatment.

\section{Acknowledgments}

Funding: None.

\section{Footnote}

Reporting Checklist: The authors have completed the STARD reporting checklist. Available at https://dx.doi. org/10.21037/apm-21-3471

Data Sharing Statement: Available at https://dx.doi. org/10.21037/apm-21-3471

Conflicts of Interest: All authors have completed the ICMJE uniform disclosure form (available at https://dx.doi. org/10.21037/apm-21-3471). The authors have no conflicts of interest to declare.

Ethical Statement: The authors are accountable for all aspects of the work in ensuring that questions related to the accuracy or integrity of any part of the work are appropriately investigated and resolved. All procedures performed in this study involving human participants were in accordance with the Declaration of Helsinki (as revised in 2013). The study was approved by ethics committee of
People's Hospital of Pengzhou (No. 2020010) and informed consent was taken from all the patients.

Open Access Statement: This is an Open Access article distributed in accordance with the Creative Commons Attribution-NonCommercial-NoDerivs 4.0 International License (CC BY-NC-ND 4.0), which permits the noncommercial replication and distribution of the article with the strict proviso that no changes or edits are made and the original work is properly cited (including links to both the formal publication through the relevant DOI and the license). See: https://creativecommons.org/licenses/by-nc-nd/4.0/.

\section{References}

1. Magoro T, Dandekar A, Jennelle LT, et al. IL-1 $1 / \mathrm{TNF}-\alpha /$ IL-6 inflammatory cytokines promote STAT1-dependent induction of $\mathrm{CH} 25 \mathrm{H}$ in Zika virus-infected human macrophages. J Biol Chem 2019;294:14591-602.

2. Kuznetsova D, Ivantsov A, Aleksakhina S, et al. P37.03 Analysis of Ddrug-Induced RNA Expression Changes in NSCLC Patient-Derived Explants as a Potential Tool for Personalized Therapy Choice. J Thorac Oncol 2021;16:S442-3.

3. Khan HA, Ibrahim KE, Alrashood ST, et al. Immunohistochemistry of IL- $1 \beta$, IL- 6 and TNF- $\alpha$ in spleens of mice treated with gold nanoparticles. Saudi J Biol Sci 2020;27:1163-8.

4. Cuellar-Núñez ML, Gonzalez de Mejia E, LoarcaPiña G. Moringa oleifera leaves alleviated inflammation through downregulation of IL-2, IL-6, and TNF- $\alpha$ in a colitis-associated colorectal cancer model. Food Res Int 2021;144:110318.

5. Pang R, Mujuni BM, Martinello KA, et al. Elevated serum IL-10 is associated with severity of neonatal encephalopathy and adverse early childhood outcomes. Pediatr Res 2021. [Epub ahead of print]. doi: 10.1038/ s41390-021-01438-1.

6. Nambi G. Does low level laser therapy has effects on inflammatory biomarkers IL- $1 \beta$, IL-6, TNF- $\alpha$, and MMP13 in osteoarthritis of rat models-a systemic review and meta-analysis. Lasers Med Sci 2021;36:475-84.

7. Alves LV, Martins SR, Simões E Silva AC, et al. TNF, IL6, and IL-10 cytokines levels and their polymorphisms in renal function and time after transplantation. Immunol Res 2020;68:246-54.

8. Alkhuriji AF, Al Omar SY, Babay ZA, et al. Association of IL- $1 \beta$, IL-6, TNF- $\alpha$, and TGF $\beta 1$ Gene Polymorphisms 
with Recurrent Spontaneous Abortion in Polycystic Ovary Syndrome. Dis Markers 2020;2020:6076274.

9. Zhang W, Wang T, Wang G, et al. Effects of Dexmedetomidine on Postoperative Delirium and Expression of IL-1 $\beta$, IL-6, and TNF- $\alpha$ in Elderly Patients After Hip Fracture Operation. Front Pharmacol 2020;11:678.

10. Bekçibaşı $M$, Deveci Ö, Oğuz A, et al. Serum TNF- $\alpha$, IL$1 \beta$, and IL-6 levels in chronic HBV-infected patients. Int J Clin Pract 2021;75:e14292.

11. Kisuya J, Chemtai A, Raballah E, et al. The diagnostic accuracy of Th1 (IFN- $\gamma$, TNF- $\alpha$, and IL-2) and Th2 (IL4, IL-6 and IL-10) cytokines response in AFB microscopy smear negative PTB- HIV co-infected patients. Sci Rep 2019;9:2966.

12. Wu GW, Chen J, Huang YM, et al. Electroacupuncture Delays Cartilage Degeneration by Modulating Nuclear Factor-kB Signaling Pathway. Chin J Integr Med 2019;25:677-83.

13. Sen N, Tanwar S, Jain A, et al. P6293 Assessment of testosterone/estradiol ratio, DHEA-S level and correlation with coronary inflammatory markers IL-1 \& 6 , TNF-1 and hsCRP predict 5 years risk of cardiovascular disease in men. European Heart Journal 2019;40:ehz746.0891.

14. Zhu Q, Zhang H, Wang J, et al. Associations of

Cite this article as: Liu Y, Gao Y, Lin T. Expression of interleukin-1 (IL-1), IL-6, and tumor necrosis factor- $\alpha$ (TNF- $\alpha$ ) in non-small cell lung cancer and its relationship with the occurrence and prognosis of cancer pain. Ann Palliat Med 2021;10(12):12759-12766. doi: 10.21037/apm-21-3471
TNF- $\alpha-238 \mathrm{G} / \mathrm{A}$, TNF- $\alpha-308 \mathrm{G} / \mathrm{A}$, and IL-6 -174G/C polymorphisms with the risk of asthma: Evidence from a meta-analysis. Pediatr Pulmonol 2020;55:2893-900.

15. Reinhardt ÉL, Fernandes PACM, Markus RP, et al. Night work effects on salivary cytokines TNF, IL-1 $\beta$ and IL-6. Chronobiol Int 2019;36:11-26.

16. Chen $M$, Ye X, Wang R, et al. Research progress of cancer stem cells and IL-6/STAT3 signaling pathway in esophageal adenocarcinoma. Transl Cancer Res 2020;9:363-71.

17. Hou D, Wang B, You R, et al. Stromal cells promote chemoresistance of acute myeloid leukemia cells via activation of the IL-6/STAT3/OXPHOS axis. Ann Transl Med 2020;8:1346.

18. Zhang X, Yang J, Bian Z, et al. Long noncoding RNA DANCR promotes nasopharyngeal carcinoma progression by interacting with STAT3, enhancing IL-6/JAK1/STAT3 signaling. Biomed Pharmacother 2019;113:108713.

19. Imai H, Kaira K, Naruse I, et al. Prospective Feasibility Study of Amrubicin and Bevacizumab Therapy for Patients With Previously Treated Advanced NSCLC. Anticancer Res 2020;40:1571-8.

(English Language Editor: C. Betlazar-Maseh) 